\title{
Rare Lytic Lesions of the Talus: A Diagnostic Challenge
}

\author{
${ }^{1}$ Vishnu Senthil, ${ }^{2}$ Vivek Pandey, ${ }^{3}$ Kiran Acharya
}

\begin{abstract}
Patients presenting with prolonged ankle pain following trivial trauma should be clinically and radiologically investigated. We present two young adults with incidentally diagnosed lytic lesion of talus. They underwent extended curettage and biopsy. Histopathological examination proved as aneurysmal and simple bone cyst and went for a secondary procedure of bone grafting. We want to emphasize the importance of differential diagnosis in the management of lytic lesions and complete removal of tumor.
\end{abstract}

Keywords: Aneurysmal bone cyst, Ankle trauma, Curettage, Simple bone cyst, Talus.

How to cite this article: Senthil V, Pandey V, Acharya K. Rare Lytic Lesions of the Talus: A Diagnostic Challenge. J Foot Ankle Surg (Asia-Pacific) 2017;4(1):49-52.

Source of support: Nil

Conflict of interest: None

\section{INTRODUCTION}

Ankle sprain is a common complaint in the outpatient department. They cause a diagnostic dilemma if they are associated with lytic lesion. We report two cases of young adults presenting with talar lytic lesions, which were incidentally found along with ankle sprain. A clinical diagnosis of bone cyst was made and proceeded with definitive management. The importance of this article is to consider various differentials during interpretation of a talar lytic lesion radiologically by an orthopaedic resident in the out-patient department.

\section{CASE REPORTS}

\section{Case 1}

The first case is a 21-year-old male presenting with pain and swelling over the left ankle of 1 week duration following twisting injury to the ankle. Patient had taken conservative management, but it did not subside. Patient was a salesman by occupation and could not stand or walk for long distances, thus hampering his income.

\footnotetext{
${ }^{1}$ Resident, ${ }^{2}$ Associate Professor, ${ }^{3}$ Professor

${ }^{1-3}$ Department of Orthopaedics, Kasturba Medical College Manipal, Karnataka, India
}

Corresponding Author: Vishnu Senthil, Resident, Department of Orthopaedics, Kasturba Medical College, Manipal, Karnataka India, e-mail: vishsnake@gmail.com
On examination, tenderness was present over the lateral malleolus. Movements of the ankle were painfully restricted. X-ray revealed a lytic lesion in the talus (Fig. 1) and computed tomography showed an intramedullary osteolytic expansile lesion with trabeculated sclerotic rim in the body and neck of the talus (Figs 2A to C). Radiologically, a diagnosis of $\mathrm{ABC}$ made. The patient underwent curettage, chemical cauterization with phenol, and iliac crest bone grafting. Intraoperative frozen section showed giant cells. Microscopic slide examination suggested $\mathrm{ABC}$ (Fig. 3). The patient was kept nonweight bearing for6 weeks in an ankle foot orthosis (AFO). Patient was madeto undergo partial weight bearing up to 3 months and with the complete incorporation of graft, he was made to undergo full weight bearing. Now, a 2-year follow-up showed no evidence of recurrence, and graft had been completely taken up with painless range of movements (Figs $4 \mathrm{~A}$ and $\mathrm{B}$ ).

\section{Case 2}

The second case was a 21-year-old male with acute onset of pain in the right ankle following a twisting injury. The patient presented with pain and swelling over the right ankle with tenderness over the lateral malleolus. X-ray showed a lytic lesion of the talus with lateral malleolus infradesmotic fracture (Figs 5A and B). The talar dome was fractured with a fallen fracture fragment. Computed

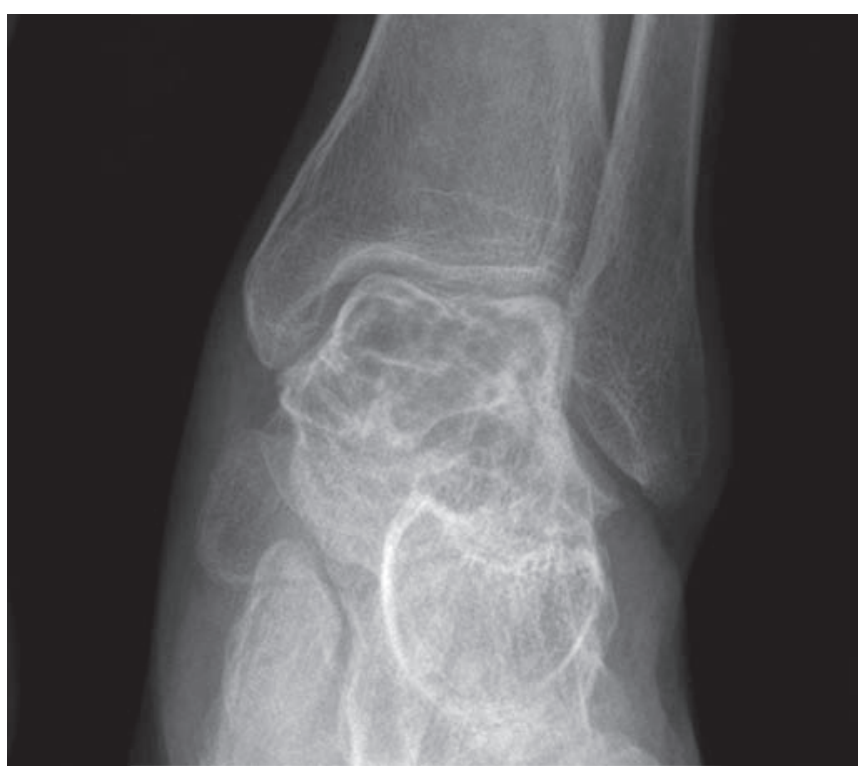

Fig. 1: Radiograph of left ankle anteroposterior view showing medullary osteolytic and expansile lesion with sclerotic rim involving the body and neck of talus 

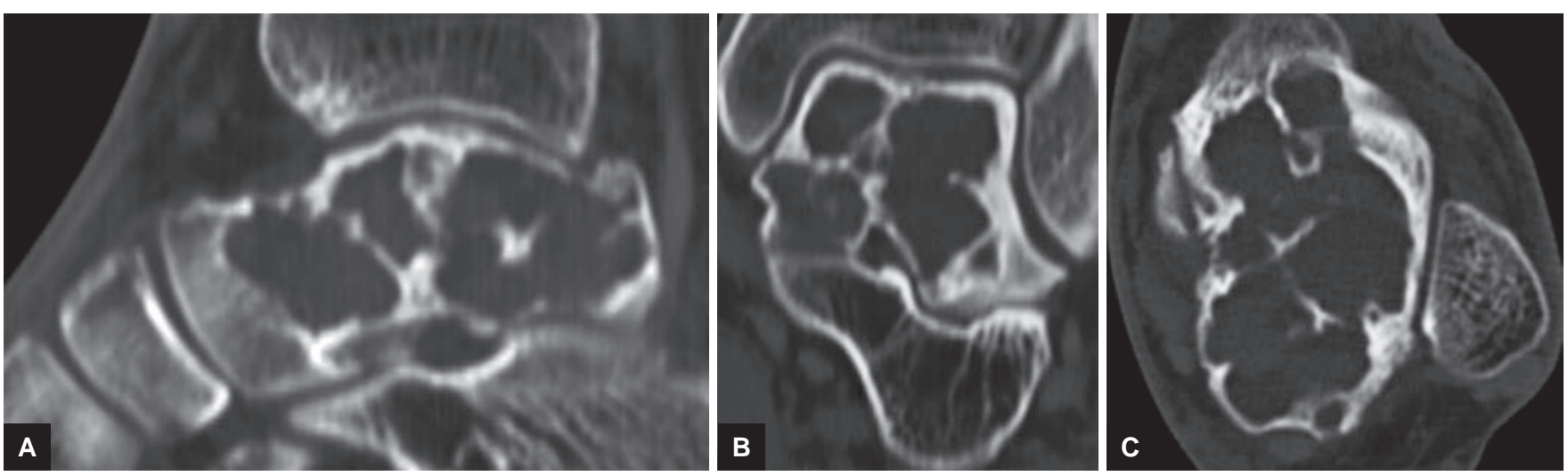

Figs 2A to C: The CT scan of left ankle coronal: (A) Sagittal; (B) axial; and (C) osteolytic and expansile lytic lesion with trabeculations of the talus

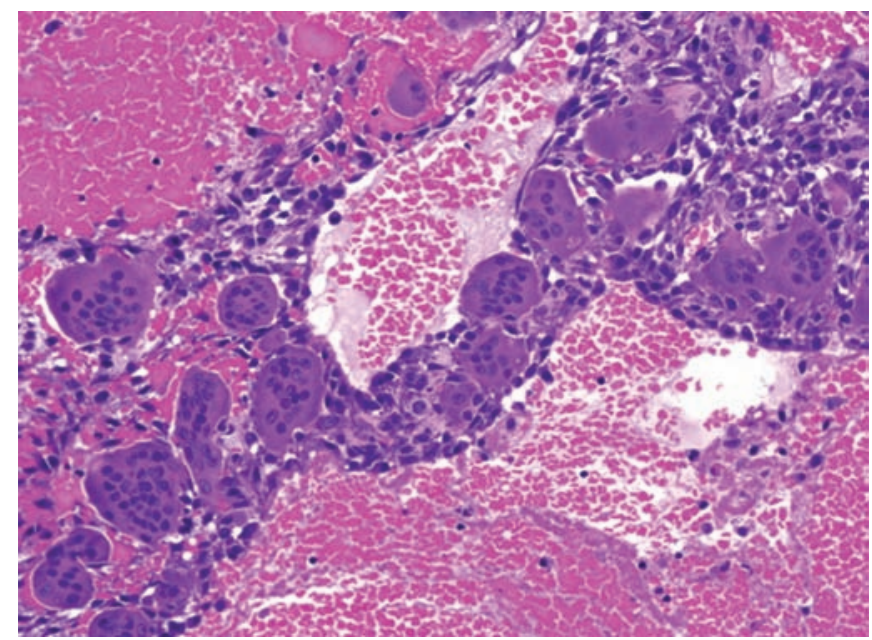

Fig. 3: Microscopic slide of $40 \times$ showing blood-filled cystic spaces devoid of lining surrounded by oval to spindle cells, hemosiderinladen macrophages and osteoclastic giant cells, macrophages, and slivers of woven bone

tomography scan showed the breakage of cyst with fragments within the cyst (Figs 6A to D). He underwent open biopsy, curettage, multiple drilling, and bone grafting from the proximal tibia with fixation of the lateral malleolus. Biopsy reported as SBC (Fig. 7). The patient was kept on nonweight bearing for 6 weeks with an AFO, and then followed by partial weight bearing. At present, 1 year following surgery there is incorporation of graft and no recurrence (Figs $8 \mathrm{~A}$ and $\mathrm{B}$ ).

\section{DISCUSSION}

Aneurysmal bone cyst was first described by Jaffe and Lichtenstein in 1942. Females are more commonly affected involving in the second decade. ${ }^{1}$ Cancellous part of the bone is affected. The $\mathrm{ABC}$ arises out of circulatory disturbances in the bone. The $\mathrm{ABC}$ arises de novo or in collision with other tumors, such as giant cell tumor (GCT), chondroblastoma, and chondrosarcoma.

Primary $A B C$ of talus is a rare entity of unknown origin and only about 30 cases have been reported in literature till 2015. ${ }^{2}$ The fine-needle aspiration cytology shows giant cells, which are also seen in GCTs. It is a locally destructive tumor showing blood-filled cavities with proliferation of fibroblast, which differentiates from SBC. ${ }^{3,4}$ Presence of mononuclear stroma with regular distribution of giant cells differentiates from GCT.
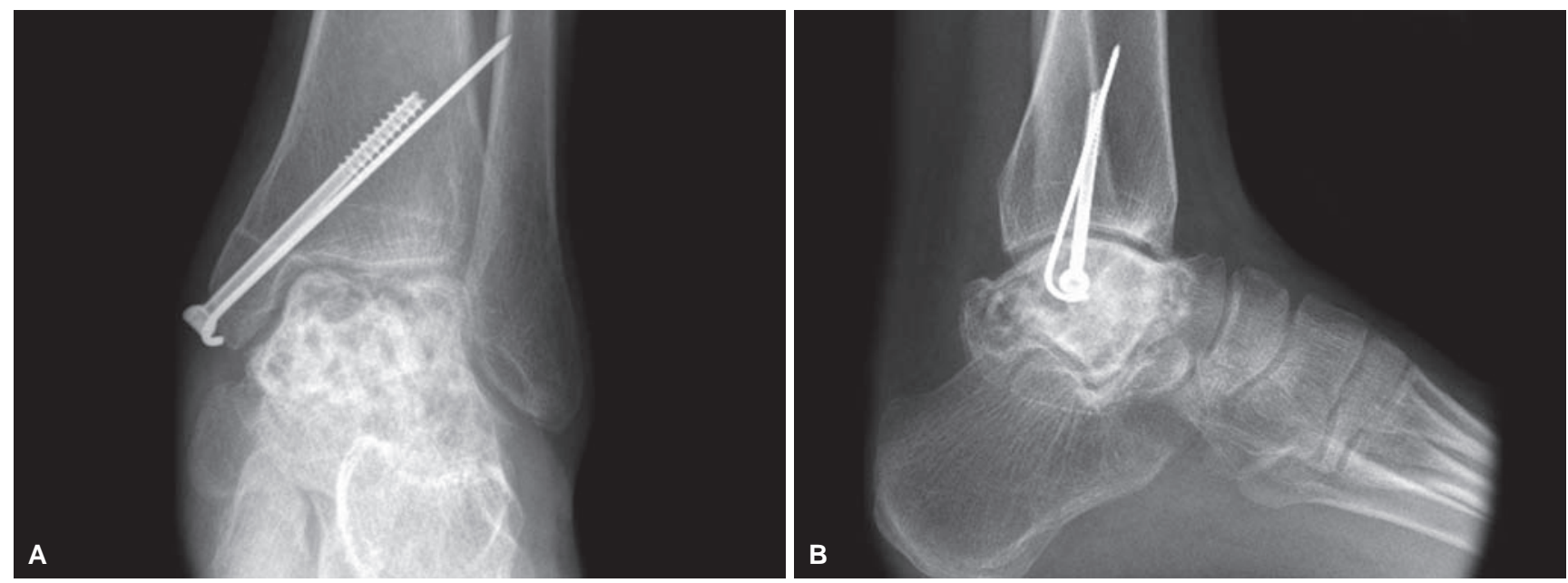

Figs 4A and B: Radiograph of left ankle anteroposterior: (A) Lateral; and (B) incorporation of bone graft in talus without evidence of recurrence 

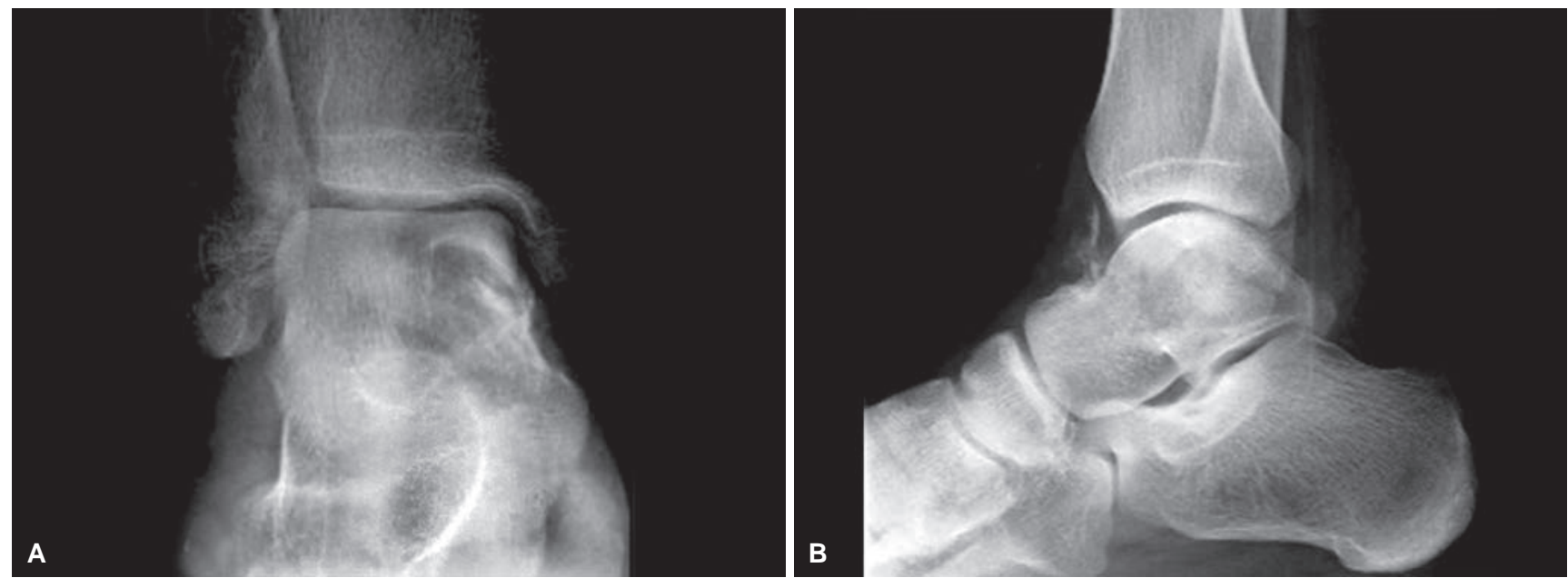

Figs 5A and B: Radiograph of right ankle anteroposterior: (A) Lateral; and (B) lytic lesion of the talus with cortical destruction with infradesmotic lateral malleolus fracture
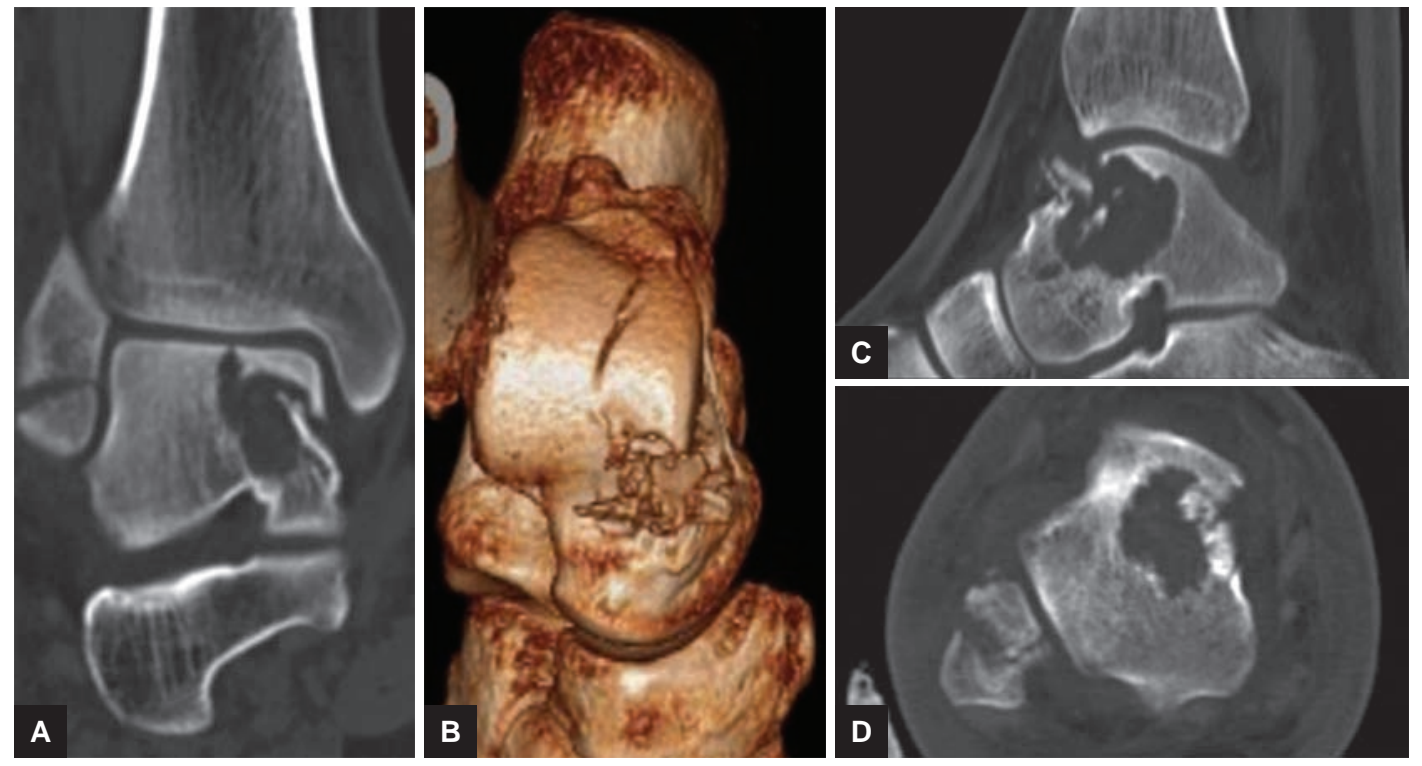

Figs 6A to D: The CT scan of ankle sagittal: (A) End-on view; (B) coronal; (C) axial; and (D) eccentric lytic lesion measuring $2.2 \times 2.5 \mathrm{~cm}$ involving neck and body of talus with geographical pattern of bone destruction. Marginal sclerosis present

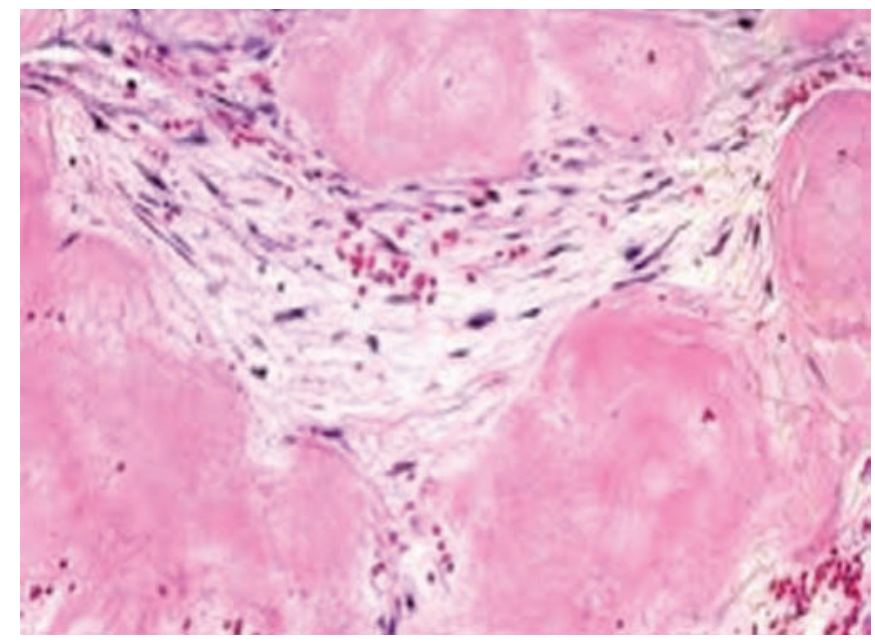

Fig. 7: Microscopic slide of $40 \times$ showing cystic spaces lined by multinucleated giant cells in fibro collagenous stroma with interspersed bony spicules
The SBC is also a common condition present in the metaphysis of the long bones. It contains straw-colored fluid. Unicameral bone cyst commonly occurs in children and presents as an active lesion in less than 10 years of age. The SBC commonly involves the proximal humerus and proximal femur.

Bone cyst occurring in talus is a rare condition. ${ }^{5}$ Many options for management are available, such as simple/ extended curettage with bone grafting. Wide extension of the lesion with ankle joint involvement, partial or complete talectomy with arthrodesis can be considered.

In our cases, we want to emphasize that patients presenting with ankle pain and not relieved with conservative management should undergo detailed clinical and radiological examination. Once diagnosed with a lytic lesion, differential diagnosis to be considered are GCT, 

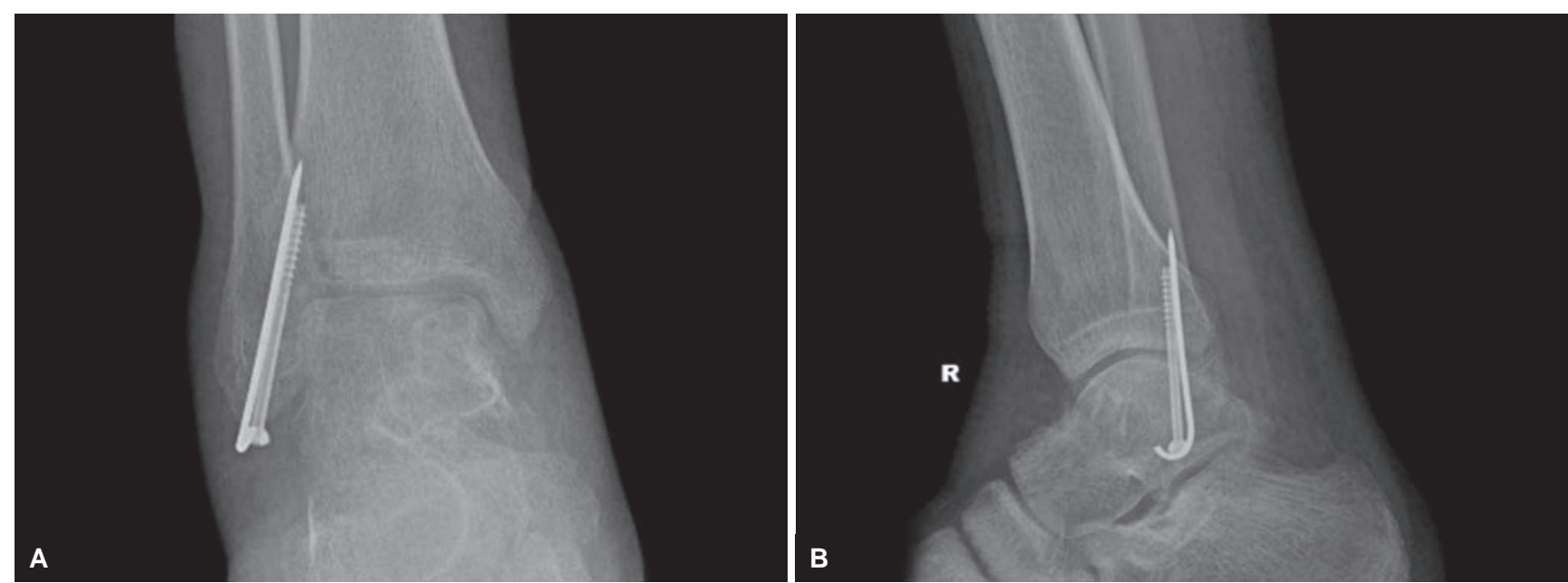

Figs 8 A and B: Radiograph of right ankle anteroposterior: $(A)$ Lateral; and $(B)$ incorporation of bone graft in the talus with no evidence of recurrence

which appears as a lytic, multiloculated epiphyseal swelling and is a common tumor of talus occurring in the age group of 20 to 40 years. ${ }^{6}$ Intraosseous lipoma (magnetic resonance imaging showing increased fat density with central calcification) and intraosseous ganglion cyst (most common) are to be ruled out. Chondroblastoma can also present as an osteolytic lesion with peritumoral edema. Complete intralesional curettage with bone grafting is needed to prevent collapse and recurrence.

In our management, we have kept the patients nonweight bearing with AFO and crutches, which had a good patient compliance, whereas in all the other reported cases, they have been immobilized with a below-knee cast.

\section{CONCLUSION}

Radiological and clinical examination in patients presenting with long duration ankle pain is very important. Aneurysmal and SBC are rare entities and should be kept as differential diagnosis in a patient presenting with lytic lesion of talus. Complete and extended curettage with bone grafting should be done. Regular follow-up is mandatory to prevent recurrence.

\section{REFERENCES}

1. Shah R, Patel J, Shah M. Primary aneurysmal bone cyst of talus - a case report. GCSMC J Med Sci 2015 Jan;4(1):62-64.

2. Taori K, Parate R, Dhakate S, Hatganokar A, Shah S, Kasat A, Patwa D, Kamble C. Aneurysmal bone cyst of talus: a rare case. Open J Radiol 2015 Jun;5:80-83.

3. Soreff J. Aneurysmal bone cyst of the talus. Acta Orthop Scand 1976 Jun;47(3):358-360.

4. Rangachari P. Aneurysmal bone cysts. Indian J Orthop 2005 Jul;39(3):174-178.

5. Kumar SH, Siddalingeshwari VH, Shukla MK, Bhadra D. Unicameral bone cyst of the talus in adult: a case report. J Evol Med Dent Sci 2015 Mar;4(26):4542-4547.

6. Dhillon MS, Singh B, Gill SS, Walker R, Nagi ON. Management of giant cell tumor of the tarsal bones: a report of nine cases and a review of the literature. Foot Ankle 1993 Jun;14(5): 265-272. 